\title{
La Exposición como Sustrato para la Educación Ambiental de un Museo de Historia Natural
}

\section{The Exhibition as a Substrate for Environmental Education in a Natural History Museum}

DIván Borroto Rodríguez ${ }^{1}$

Marília Andrade Torales Campos²

'Universidade Federal do Paraná (UFPR), Programa de Pós-Graduação em Educação, Curitiba, PR, Brasil.

${ }^{2}$ Universidade Federal do Paraná (UFPR), Departamento de Teoria e Prática de Ensino, Curitiba, PR, Brasil. Autora Correspondiente: marilia.torales@ufpr.br

Resumen: Este artículo discute la presentación del medio ambiente y sus problemas en la exposición del museo de historia natural, así como analiza la presentación del medio ambiente y de problemas ambientales en el caso particular de la exposición del Museu Oceanográfico Univali, de Balneário de Piçarras, estado de Santa Catarina, en Brasil, como substrato para la educación ambiental de sus públicos. Para tal propósito, se desarrolló una investigación en el marco del paradigma cualitativo-interpretativo. Como resultado fue posible identificar a la exposición como una acción de educación ambiental de carácter conservacionista en el marco de un abordaje conductista.

Palabras clave: Museo de historia natural; Educación ambiental; Medio ambiente; Colección museológica; Educación en museos.

Abstract: This article discusses the presentation of the environment and its problems in Natural History museum exhibitions, as well as the presentation of the environment and environmental problems in the particular case of the exhibition of Museu Oceanográfico Univali, of Balneário de Piçarras, Santa Catarina State, Brazil, as a substrate for the development of visitors' environmental education. For this purpose, a study was developed within the framework of the qualitative-interpretative paradigm. As a result, it was possible to identify the exhibition as an environmental education action of a conservationist nature within the framework of a behaviourist approach.

Keywords: Natural history museums; Environmental education; Museological collection; Museum education.

Recebido em: 11/10/2019

Aprovado em: 11/01/2021 


\section{Introducción}

El reconocimiento y la preocupación por el estado de crisis ambiental planetaria muchas veces lleva a museos de historia natural a orientar sus acciones educativas en dirección a la educación ambiental de sus públicos, lo que ha sido reconocido en la literatura científica por autores como Delicado (2004), Fortin-Debart (2003) y Marandino (2005), entre otros.

Frente a esa situación, reflexionar sobre la presentación del medio ambiente y cuestiones afines en las exposiciones se hace cada vez más necesario, pues estas se constituyen en el principal medio de comunicación del museo con sus públicos, así como también en su principal acción educativa en cuanto a número de visitantes beneficiados. En esa perspectiva se sitúa el presente trabajo, que tiene por finalidad discutir la educación relativa al medio ambiente de un museo de historia natural, tomando por base el análisis de sus exposiciones.

Las lógicas científicas desarrolladas durante los tres siglos de existencia del museo de historia natural y sus formas particulares de entender la naturaleza, objetivo de sus estudios, han atravesado históricamente toda la organización del museo. A partir de Kury y Camenietzki (1997) es posible entender que esas lógicas científicas y sus visiones de naturaleza han sido representadas en las exposiciones mediante ordenaciones particulares del acervo y la presentación de temas científicos. Por otra parte, siguiendo a Hooper-Greenhill $(2004,2007)$ y Hein (2002), se puede afirmar que el museo de historia natural a partir del siglo XX, en el deseo de conectar con el público y atraer a un mayor número de visitantes, ha incorporado en las exposiciones modificaciones e innovaciones didácticas, lo que se traduce en la entrada de modelos y teorías de la educación y de la comunicación al espacio expositivo.

Esa intencionalidad didáctica presente en las exposiciones permite pensarlas como una acción educativa. Si bien en el mundo de los museos esa opinión no es consensual, se considera para los propósitos del presente estudio, en sintonía con Maradino (2011, p. 22, traducción de los autores), que "[...] cualquier acción material, propuesta, objeto, etc. planeado con intenciones de enseñanza y divulgación y que busque el aprendizaje y la producción de significados junto al público es educativa (o) y simultáneamente comunicativa (o)".

Las exposiciones del museo de historia natural, de acuerdo con Fortin-Debart (2003), cumplen con una función pedagógica de mediación ambiental, en consonancia con los cambios acontecidos en el museo y en las ciencias que tienen como objeto de estudio la naturaleza. Si se piensa junto a Cury (2013) que el potencial educativo de la exposición se efectiva a partir de la incorporación del mensaje al cotidiano de las personas, pues entonces no parece ilógico pensar que las exposiciones del museo de historia natural en su función de mediación ambiental, pueden educar ambientalmente a sus visitantes.

A partir de los presupuestos anteriores se considera posible realizar una lectura analítica de las exposiciones, más allá de su contenido evidente, mediante una mirada situada teórica e metodológicamente, capaz de desvelar representaciones, conceptos y procedimientos, que coadyuven con los objetivos del presente estudio. En esa línea de pensamiento se sitúa Marandino (2009) quien opina que a partir del estudio de la museografía de las exposiciones es posible comprender las 
concepciones de ciencias y educación asumidas. Así, de la comprensión de los estilos de educación y comunicación, siguiendo a Meyer y Meyer (2014), podrá tenerse una comprensión en profundidad de la Educación Ambiental en esos espacios.

En el ámbito de museos de historia natural, la educación ambiental ha sido pensada en diálogo con la educación en ciencias que históricamente se desarrolla en estas instituciones. En ese sentido, autores como Vasconcellos y Guimarães (2006), Meyer y Meyer (2014) y Lamim-Guedes (2017) defienden un dialogo de la educación en ciencias con vertientes críticas de la educación ambiental, en base a su potencial transformador y al componente político y social que la última puede incorporar a la primera. No obstante, puede suceder con bastante frecuencia que la educación ambiental en el museo choque con su estructura disciplinar, y en consecuencia se desarrolle como una educación ambiental reductora en el abordaje de las problemáticas ambientales, desde que no es capaz de abarcar sus dimensiones sociales, éticas, políticas e ideológicas, etc., que hacen parte de su naturaleza compleja.

La educación ambiental es un campo diverso y heterogéneo, "[...] caracterizado por una gran diversidad de teorías y de prácticas que abordan desde diferentes puntos de vista la concepción de educación, de medio ambiente, de desarrollo social y de educación ambiental" (SAUVÉ, 2003, p. 20). Así, de acuerdo con Sauvé (2010), la educación ambiental a partir de su heterogeneidad puede entrecruzarse con la educación en ciencias de diversas maneras complementarias, algo que con seguridad sucede en el museo de historia natural y de lo cual puede inferirse el rol político del museo ante su sociedad.

\section{El Medio Ambiente en la Exposición del Museo de Historia Natural}

El medio ambiente siempre ha estado presente en las exposiciones del museo de historia natural. Esa aseveración, surgida del análisis de la evolución de esta institución a lo largo del tiempo, no debería parecer rara si se piensa que:

\footnotetext{
Nature and the environment weave relationships with museums that are subject to scientific and social representations that our societies have had in the past, and continue to have today, not only of nature, but also of heritage and, of course, museums (VAN PRAËT, 2004, p. 114).
}

El museo de historia natural ha ido experimentando un proceso de transformación desde sus orígenes hasta nuestros días, influido fundamentalmente, por los cambios sufridos por las ciencias naturales hasta comienzos del siglo XX, y a partir de la segunda mitad del siglo XX, por la influencia de áreas del conocimiento que se ubican más allá de las ciencias naturales como la museología y la comunicación.

Las colecciones de los primeros museos de historia natural, durante los siglos XVI, XVII y XVIII, fueron herederas y mantuvieron similitudes con aquellas presentes en los gabinetes de curiosidades, que eran representativas de una naturaleza rara y singular. Esas colecciones, que podían incluir y mostrar hasta objetos de atribuida naturaleza mitológica, eran organizadas a partir de la división básica de los tres reinos de la naturaleza: vegetal, animal y mineral (KURY; CAMENIETZKI, 1997). Además, según Hooper-Greenhill (2003), eran representativas de formas medievales de conocer, dependientes de pruebas no verificables, que no distinguían entre lo percibido y lo imaginado. 
A lo largo del movimiento de transición de los gabinetes de curiosidades a museos de historia natural, las colecciones también fueron cambiando, a partir de la participación de los museos de historia natural en el desarrollo de nuevos sistemas científicos de clasificación. Esos sistemas, al interior del acervo, se tradujeron en una nueva organización de las piezas a la luz de criterios taxonómicos, que se proponían clasificar y organizar el mundo natural mediante el hallazgo de diferenciaciones como resultado de la comparación de estructuras visibles (HOOPER-GREENHILL, 2003).

Esa forma de presentación del acervo del museo, según Fortin-Debart (2003), puede ser entendida como expresión de una representación biocéntrica del medio ambiente, pues en ella los especímenes aparecen siguiendo un orden taxonómico, entendiéndose el medio ambiente como naturaleza, representada a partir de sus elementos plantas y animales.

Al tener una única colección, en el caso de que el museo fuera público, podía producirse una tensión entre el interés del museo por conservar e investigar el acervo y el interés por exponerlo. Esa tensión va a resolverse en el siglo XIX, siguiendo a Van Präet (1996), con el surgimiento de las exposiciones temáticas, pues con ellas ya no se necesita mostrar todo el acervo al público en la misma forma que es utilizado por los científicos. Este cambio, según el autor, deriva en la disociación del espacio del museo entre el área de almacenamiento de las piezas y el espacio de la exposición de las mismas, dando origen al museo moderno.

Las exposiciones temáticas surgen como resultado de un cambio en el discurso expositivo, que de intentar presentar toda la diversidad del mundo pasa a contar conceptos e ideas científicas. Este cambio es posible, según Hooper-Greenhill (2003), pues para esa época las ciencias naturales alcanzan un nuevo estadio, en el que además de clasificar los organismos a la luz de taxonomías científicas, pasan a ofrecer explicaciones a partir del conocimiento de las estructuras internas de los organismos y de sus funciones, así como de sus relaciones con el ambiente. En esas exposiciones, resultado de una selección intencionada de piezas a partir del acervo, siguiendo a Hooper-Greenhill (2004), la propia selección da forma a la narrativa visual que se presenta, y los ensamblajes que se construyen entre los objetos invocan diferentes contextos de significado.

Para Van Präet (1996), las exposiciones temáticas Ilegan a su óbice con la invención del diorama, recurso museográfico que demanda de objetos preparados especialmente con fines didácticos y escenográficos para contar ideas surgidas en el campo de la ecología. En este recurso museográfico, Fortin-Debart (2003) reconoce una representación del medio ambiente ecocéntrica, pues el espécimen ya no se presenta solo, sino insertado en una reconstrucción tridimensional y aproximada de su entorno natural, donde se muestran las interacciones naturales entre plantas y animales, e incluso con elementos abióticos del entorno.

Museos de historia natural, surgidos desde el siglo XVI hasta el siglo XIX, principalmente, lo que no excluye a museos de épocas posteriores con características similares, pertenecen según McManus (1992), a un primer momento de la primera generación de museos de ciencias, caracterizada por mantener fuertes filiaciones con disciplinas académicas en las universidades y por tener como primer propósito, el de contribuir al conocimiento científico. Las exposiciones de estos museos, según la autora, semejantes a libros de textos tridimensionales, ricas en objetos, eran o son preparadas por curadores, que se encargan de la selección de las piezas, la confección de las etiquetas, 
y de entregar el lote a un diseñador que las coloca en vitrinas. En el caso de existir educadores, no intervienen en la creación de las exposiciones, solo en su interpretación verbal durante el atendimiento a visitantes y escolares.

Entrado el siglo XX, décadas del 70 y del 80, según McManus (1992), los profesionales de los museos de historia natural ante las limitadas cualidades comunicativas de las exposiciones, que no garantizaban ser comprensibles y esclarecedoras para el público, abogan por transformaciones dirigidas a sustituir el enfoque taxonómico por la presentación de conceptos e ideas actuales, así como por la creación de exposiciones atractivas con informaciones cuidadosamente estructuradas, que involucren al visitante, y con las que podrían interactuar. Estas transformaciones, según la autora, llevan a pensar en un segundo momento, dentro la primera generación, integrado por museos que dan un destaque a su función educativa, sustentado en la creación de sectores educativos más sofisticados y con más recursos a su disposición.

Para Cury (2006), los cambios experimentados por los museos en la segunda mitad del siglo XX, afectaron la visión del museo tradicional y su praxis museográfica. En este sentido, los museos comenzaron a manifestar un creciente interés por la educación y el trabajo con sus públicos, implementando en consecuencia prácticas evaluativas en sus productos museográficos. No obstante, según la autora, para el caso particular de Brasil, no es frecuente la realización de prácticas evaluativas en instituciones museológicas. Este fenómeno, argumenta la autora, podría deberse a la falta de un referencial teóricometodológico apropiado para el desarrollo de estos procesos, a la existencia de una conciencia en los museos que si bien reconoce la necesidad de estos procesos no es suficiente para su implementación, y a la falta de recursos humanos y materiales.

A partir de la segunda mitad del siglo XX, ante la situación de crisis ambiental que se comienza a percibir en el mundo, los museos de historia natural no se mantienen ajenos a esta situación y comienzan a incluir en sus exposiciones la problemática ambiental. Esta presentación de problemas ambientales en las exposiciones, según Fortin-Debart (2003), se corresponde con una representación antropocéntrica del medio ambiente, pues se presenta al ser humano como centro del mundo y al medio ambiente como un recurso a ser conservado en relación a las necesidades de la humanidad, que reclaman por la supervivencia, la salud, y la calidad de vida de los seres humanos.

La representación antropocéntrica, según esta autora, se relaciona con un nuevo estado alcanzado por la ecología científica, que por la décadas del 1960 y del 1970, toma en cuenta las preocupaciones de los individuos y sus sociedades en relación al medio ambiente. Esas preocupaciones son abordadas en las exposiciones al mostrar problemas ambientales relacionados con la acumulación de residuos sólidos, la contaminación del agua y las alteraciones del clima.

Por esta misma época, la educación ambiental comienza a extenderse internacionalmente, motivado por la celebración de reuniones internacionales y el desarrollo de programas de apoyo auspiciados por la Organización de las Naciones Unidas (ONU) y el Programa de las Naciones Unidas para el Medio Ambiente (PNUMA), para su entrada a instituciones educativas de carácter formal y también no formal, de la cual no se excluye a los museos. Esta primera educación ambiental, según GonzálezGaudiano (2001), de carácter conservacionista, manifestaba un énfasis en las ciencias naturales, y en una concepción de aprendizaje acorde con la psicología conductista. 
Los problemas ambientales abordados por la educación ambiental a la luz de las ciencias naturales, de carácter positivista y mecanicista, generalmente son tratados en su dimensión biofísica, desligados de las prácticas sociales y culturales, lo que invariablemente aporta a la educación ambiental un matiz conservacionista. Para compensar esta fragilidad, Foladori (2002) propone que en el tratamiento de los problemas ambientales, no sean abordadas solamente las causas y consecuencias técnicas de los mismos, explicadas a la luz de las ciencias naturales, sino además, que se explicite los responsables de tales causas y los beneficiados y perjudicados de las consecuencias a la luz de las ciencias sociales. Este movimiento contribuiría a la incorporación de un matiz reflexivo, aproximando la educación ambiental de prácticas educativas de carácter social y crítico.

Próxima a este abordaje, Fortin-Debart (2003) propone una última representación del medio ambiente con el propósito de agregar la dimensión sociocultural a las representaciones del medio ambiente presentes en las exposiciones de museos de historia natural. Esta representación denominada por la autora como sociocéntrica, se caracteriza por centrarse en los componentes socioculturales del entorno, permitiendo repensar varias relaciones con el medio ambiente como la relación entre la ciencia y la política, la ciencia y la sociedad, entre otras.

A partir de esta breve construcción histórica se puede inferir, grosso modo, que el camino recorrido por el museo de historia natural ha orbitado en función de establecer y socializar un orden para la naturaleza, en función de las lógicas científicas dominantes en cada época. Así, el museo llega al siglo XXI condicionado por los procesos experimentados y estructuras creadas en los siglos anteriores; pero también bajo la influencia de nuevas exigencias de la sociedad en dirección de su democratización, de la inclusión de problemas contemporáneos en su discurso, y de un mayor dinamismo y participación del público en sus funciones.

\section{La Colecta de los Datos en el Museo Oceanográfico Univali}

En el ánimo de comprender como un museo de historia natural de la actualidad presenta al medio ambiente y problemas ambientales en sus exposiciones, se eligió para el estudio al Museu Oceanográfico Univali, ubicado en Balneário de Piçarra, en el litoral del estado de Santa Catarina, en Brasil.

El estudio se realizó sobre el presupuesto, que mediante el análisis de la exposición, a la luz de conocimientos provenientes de la museología y de la educación ambiental, es posible comprender el papel educativo-ambiental del museo en el trabajo con sus públicos y frente a la situación de crisis ambiental.

El análisis de la exposición se desarrolló a la luz del paradigma cualitativointerpretativo, caracterizado según Alves-Mazzotti y Gewandszajder (2000), por ser un abordaje intuitivo, holístico y naturalista, características presentes durante el estudio. En este marco fueron usados varios métodos para la obtención y cruce de informaciones como son la observación, la entrevista y la revisión de documentos.

En el caso de la observación de la exposición, se realizó al ritmo marcado por el investigador, quien auxiliándose de una libreta de notas y de una guía de observación, fue realizando una descripción preliminar. En paralelo, el investigador fue tomando 
fotos de cada elemento integrante de la exposición, así como también tomó pequeños videos para el análisis exhaustivo y descripción final.

El modelo de entrevista adoptado fue el de entrevista semi-estructurada, para el que fue desarrollado con anterioridad una guía de temas, con la intención de insinuar un camino a seguir durante la entrevista realizada a uno de los integrantes del equipo creativo de la exposición.

En la investigación se revisaron, principalmente, los textos de apoyo presentes en la exposición, pues no se encontró algún documento en relación a la concepción y montaje de la exposición.

\section{La Exposición del Museo Oceanográfico Univali}

\section{Presentación del Museo}

El Museu Oceanográfico Univali está localizado en el municipio Balneário de Piçarras, próximo a la BR 101, en el estado de Santa Catarina, región sur de Brasil. Es un museo universitario de historia natural, que posee una nutrida colección de especímenes marinos, representativa de la fauna de costas y mares de Brasil.

La institución es amparada desde el año 1987 por la Universidade do Vale do Itajaí (Univali), que cedió al museo su sede actual, un amplio y moderno edificio docente de cuatro pisos, ocupado casi en su totalidad por el museo. En su primer piso se sitúa la exposición, de fácil acceso a los visitantes, ocupa aproximadamente 1000 metros cuadrados y expone parte de la colección del museo.

El servicio público de la institución fue inaugurado en su sede actual en el año 2015, con la apertura de la exposición al público. En la actualidad cuenta, además, con un equipo educativo que se encarga de realizar visitas mediadas a las exposiciones, principalmente para los escolares de la región, durante el año lectivo, de martes a viernes. Los fines de semana y durante las vacaciones escolares la exposición es visitada por el público espontáneo.

\section{Presentación de la exposición}

La exposición (figura 1) es un arreglo museográfico construido a partir del uso intensivo y extensivo de módulos ${ }^{1}$, que portan vitrinas, acuarios, paneles y carteles. Este recursos museográfico, permite el aumento del área expositiva constituida, mayormente, por numerosos corredores angostos, que prácticamente empujan al visitante en una sola dirección, pretendiendo que la exposición sea consumida secuencialmente y en toda su extensión.

El recorrido por la exposición (figura 1) va atravesando unidades temáticas, identificadas por el color particular de sus paredes. Así, la primera unidad temática es el ala azul, que expone, principalmente, piezas como testimonio de la relación histórica del hombre occidental con el océano, mediada antes de la modernidad por los mitos y leyendas, y a posteriori por el desarrollo de la ciencia y la tecnología, en particular la oceanografía. El resto de las unidades temáticas, demarcan grandes grupos zoológicos

'Estructuras o armazones de madera, cartón y alfombra que funcionan en la exposición como paredes, de más de dos metros de altura. 
que en su interior manifiestan una organización jerárquica en grupos taxonómicos. Estas grandes unidades temáticas se disponen secuencialmente, en orden de complejidad, con base en una lógica evolutiva. En estas unidades temáticas, además, en una menor proporción, se exponen objetos como testimonio del consumo y explotación de algunas de las especies representadas, así como de la presencia de algunas especies en la cultura de pueblos de diferentes partes del planeta.

Figura 1 - Croquis aproximado de la exposición del Museu Oceanográfico Univali

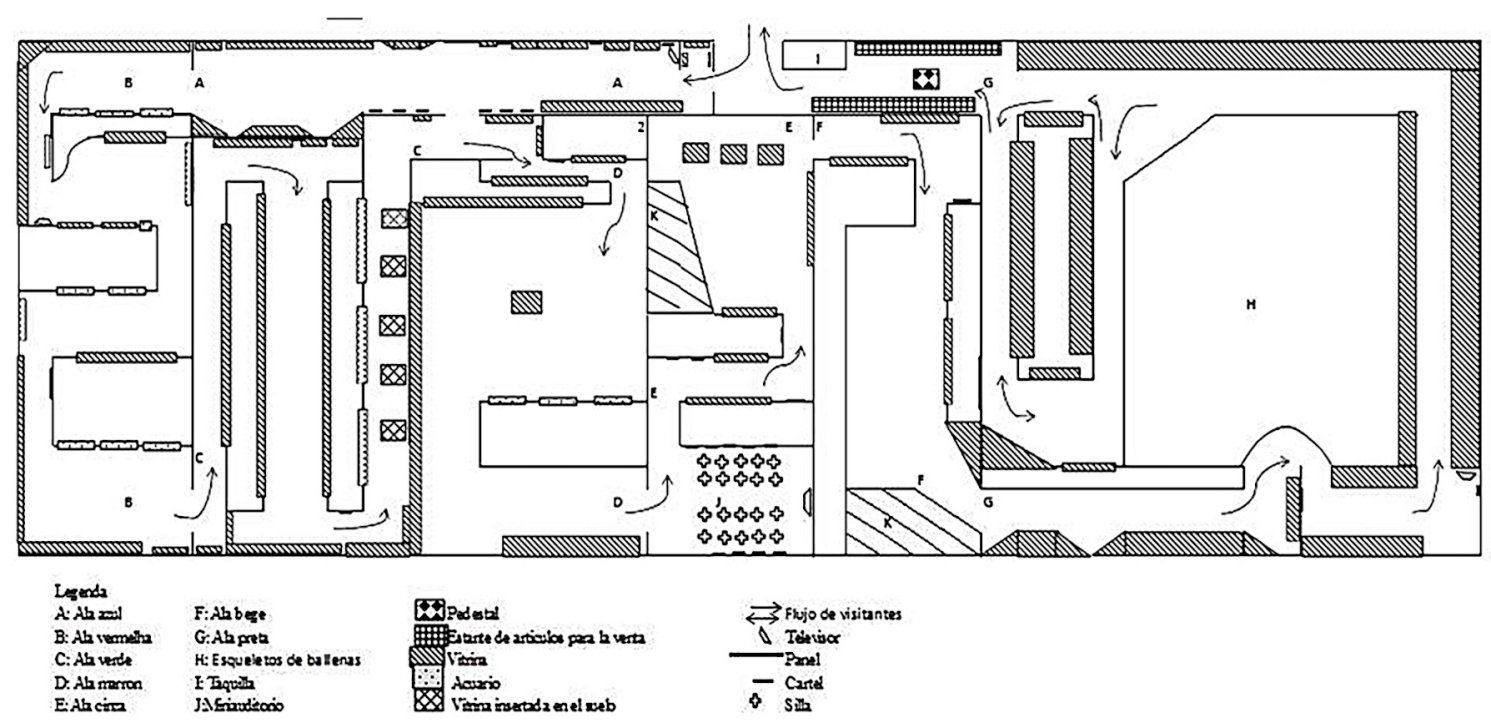

Fuente: elaboración de los autores.

Los objetos y especímenes son mostrados al público, principalmente en vitrinas, lo que privilegia a la observación como el principal modo de interacción del visitante con la exposición. Los especímenes se exhiben taxidermizados, en preparaciones liquidas, así como sus esqueletos reconstruidos, huesos y estructuras dérmicas, entre otras piezas que remiten a las especies. En el caso de especímenes vivos, estos son mostrados en acuarios. Dos grandes vitrinas, además, figura 1 (letra K), muestran especímenes en el contexto de dioramas.

La presencia de información textual en apoyo a las piezas expuestas es bastante frecuente, a pesar de no estar totalmente terminada la colocación de rótulos en la exposición. En este sentido, existen tramos que, de acuerdo con Dean (2002), pueden clasificarse como conceptuales, pues la información textual es abundante y decisiva para la comprensión de lo expuesto. Es el caso del ala azul donde los objetos se agrupan en función de las ideas que el equipo creativo quiere comunicar mediante la información textual. Estos tramos, semejantes a libros de textos, parecen ignorar que los visitantes hacen el recorrido a pie, en el marco de una visita con fines educativos pero también de deleite. Por otra parte, otros trechos de la exposición, menos frecuentes, poseen poca información textual. En estos casos, los objetos se agrupan por temas o abordajes clasificatorios que pueden ser entendidos a partir de la contemplación del conjunto. Este tipo de abordaje puede ser observado en el ala vermelha (roja), en una gran vitrina que a todas luces intenta mostrar la gran diversidad del grupo de los moluscos bivalvos, a través de la exposición de numerosas conchas con diversas formas, colores y tamaños, etc. 
Carteles y paneles son otros de los recursos expositivos ampliamente utilizados en la exposición. Poseen toda una variedad de formatos y cumplen diferentes funciones. Así, algunos son usados con la intención de anunciar el grupo taxonómico expuesto en la sala. En este caso, portan sellos postales con imágenes de especímenes y un título con el nombre común del grupo. Otros carteles, tratan temas, generalmente relacionados con el conjunto expositivo del cual forman parte. Para tal propósito, poseen fotos, ilustraciones y/o diseños en relación con el tema, un título breve y textos. Algunos paneles y carteles son utilizados para mostrar al público diseños a escala real de animales que por sus grandes dimensiones no pueden ser expuestos al público.

\section{Concepción y montaje de la exposición}

La exposición es el resultado de aproximadamente cinco años de trabajo de un equipo creativo integrado por profesionales del museo de disimiles formaciones: geógrafo (1), biólogo (2), historiador (1), periodista (1). De ellos, el curador principal, geógrafo de formación, asumió un papel protagónico en la conceptualización, coordinación de los trabajos y búsqueda de recursos para la exposición, mientras que el resto asumieron funciones más relacionadas con el montaje, en el marco de un proceso, al parecer, colaborativo, sin obviar la jerarquía del curador principal. Este estilo de trabajo puede percibirse en la opinión de la entrevistada cuando opina:

Essa exposição começou a ser pensada há muito tempo. Antes mesmo de a gente ter um espaço para
fazer essa coleção, o curador já pensava nessa exposição. Então tem muitas peças da coleção que ele já
tinha na cabeça dele.

O curador ordenando os trabalhos, ele pensava, daí jogava as ideias no grupo. A gente ia lá, nas salas. Aí todo mundo discutia, pensava, e todo mundo dava sua opinião. [...]. Cada um pensou de uma maneira com o que estava fazendo, mas todo o mundo pensando a mesma coisa, discutindo ali, no momento.

El proceso de creación de la exposición parece haber sido, más bien, un proceso que ha transcurrido puertas adentro de la institución, sin tener en cuenta a los públicos del museo. Un proceso marcado por la empírea, desarrollado in situ, pues fue en el espacio expositivo donde se fueron adaptando las idealizaciones al acervo seleccionado, a las posibilidades del espacio y de los materiales conocidos por el equipo, así como a los recursos financieros disponibles. Esta afirmación toma vida en las palabras de la entrevistada cuando opina sobre el proceso de montaje de la exposición. En este sentido se exponen algunos fragmentos:

Não fizemos nenhum tipo de estudo porque a gente já sabia o que ia ser, baseado em toda a história dos museus de história natural. Eles têm um caminho próprio, porque eles chamam a atenção de todo mundo, ele não tem um público específico, que a gente precisasse direcionar.

Quando a gente determinou que esse espaço aqui em cima, seria o espaço de uma exposição de caráter mais de longo prazo, então a gente começou a imaginar esses espaços de acordo com o que se imaginava expor.

Quando nós começamos a montar a primeira sala, foi a sala dos répteis. A gente ainda não sabia como ia ser a sala dos peixes que estava antes, e a gente ainda não sabia como ia a ser o museográfico da sala das aves, que seria o próximo. Isso estava mais o menos na cabeça, mas a gente não tinha, assim, estipulado determinadamente. 
Una vez montada la exposición y abierta al público, aunque no se considera terminada, sus creadores se mantienen sensibles a algunos canales de retroalimentación, que tienen en cuenta la interacción del visitante con la exposición. Estas informaciones provenientes del espacio expositivo, al provocar cambios en la exposición, traslucen un interés del equipo creativo por conectar con el público del museo. Este hecho puede ser apreciado en el proceso de transformación acontecido con los acuarios que forman parte de la exposición, que ante la poca aceptación del público, pasaron de mostrar una especie viva para que fueran apreciadas sus características a exponer varias especies. En relación con este tema, la entrevistada opina:

Inicialmente, os aquários... eles tinham temas, depois a gente abriu esse tema. A gente viu que não ia a ficar um aquário bonito se a gente mantivesse o tema.

A gente foi transformando por uma questão, assim, de que a gente queria que ele fosse educativo, mas se ele não era esteticamente interessante, ele perdia a função educativa, porque as pessoas simplesmente não ol havam ele, não chamava a atenção, sabe! Ele perdia a atratividade. A gente foi enriquecendo esses aquários e de alguma maneira tornando eles mais bonitos e misturando um pouquinho os temas, não sendo tão rigoroso em relação aos temas.

Si bien, cambios como este apuntan a una preocupación del equipo creativo por la comunicación con el visitante y por el desarrollo del potencial educativo de la exposición; por otra parte, las decisiones en dirección al reajuste son tomadas a posteriori del montaje, lo que puede dificultar posibles cambios y probablemente encarecer los costos de la exposición. Además, las informaciones provenientes del espacio expositivo están más en función de la experiencia como observadores de los integrantes del equipo, en el marco de observaciones casuales e informales, lo que coloca cierta incertidumbre sobre los cambios producidos en pos de la inteligibilidad de la exposición; aunque, desde una perspectiva optimista, estos cambios pueden ser interpretados, de acuerdo con Figurelli (2014, p 153), como "[...] uma atitude pertinente e que guarda a relevância do princípio de uma prática a ser adotada".

No obstante, se puede afirmar que de forma general las informaciones colectadas apuntan a la presencia y prevalencia de un proceso comunicacional de naturaleza unidireccional en la interacción de los visitantes con la exposición, desde que no han sido tomados en cuenta para la elaboración del mensaje. De acuerdo con HooperGreenhill (2010), ese estilo de la comunicación, con base en una visión conductista de la enseñanza, se construye sobre una asimetría en la cual el emisor, en este caso el científico/curador, ostenta el poder de definir y controlar el mensaje, y el receptor (visitante), únicamente es considerado en relación a la correcta recepción pasiva del mismo.

La frecuente presencia de ese tipo de abordaje en el espacio expositivo es destacada por Falk, Dierking y Adams (2006) y Cury (2011), quienes opinan que más allá de la presencia de enfoques focalizados en el receptor, el abordaje conductista continúa prosperando en el espacio expositivo. A título de ejemplo, Falk, Dierking y Adams (2006) opinan que muchos profesionales de museos de ciencias ajustan parámetros ambientales del espacio expositivo y recursos expográficos, como si los visitantes llegaran al museo teniendo la misma experiencia y habiendo aprendido exactamente lo mismo. 


\section{El medio ambiente y los problemas ambientales en la exposición}

Más allá del ala azul, dedicada a testimoniar la relación del hombre con el océano, mediada por su afán de conocimiento y conquista, el tema central para el resto de la exposición lo constituye la biodiversidad de animales marinos de Brasil. Este tema a su vez abarca subtemas relacionados con la distribución geográfica, la biología, el comportamiento y el estado de amenaza de las especies representadas en los especímenes expuestos, que al estar organizados, mayormente con base en una ordenación taxonómica, transparentan una representación del medio ambiente biocéntrica.

Con menor representatividad, los especímenes también son expuestos en el marco de una representación ecocéntrica del medio ambiente, la que puede ser percibida en los dos dioramas presentes en la exposición. Esta representación también puede ser percibida en los acuarios, que en un intento de reconstrucción de ambientes marinos, muestran diversas especies que establecen relaciones entre sí y con los elementos no vivos de su reducido entorno.

La representación ecocéntrica del medio ambiente identificada en dioramas y acuarios parece ser reforzada por otros recursos museográficos que integran la exposición. En estos recursos, al parecer, se intenta relativizar la posición del ser humano como especie superior y dominante, en dirección a una posición ecocéntrica que lo coloca como un ser ecodependiente, y que "[...] destituído de qualquer recorte social, considera-o exclusivamente na sua condição de espécie biológica" (LAYRARGUES, 2012, p. 405).

Así, la presencia de paneles y carteles con diseños de animales marinos a escala natural, que destacan por su gran tamaño en el reino animal, se interpreta como un recurso que pretende el asombro del visitante y su empequeñecimiento ante la magnificencia del mundo animal, y en consecuencia situarlo como un organismo más en la compleja trama de la vida.

Por otro lado, en los documentales 0 oceano ${ }^{2}$ y $O$ recife de coral ${ }^{3}$, proyectados en televisores, uno en el ala azul y otro en el ala vermelha (roja, figura 1), se presenta al ser humano como un organismo más en la trama de la vida del planeta, en una relación de dependencia con el mundo natural. En el marco de esta lógica, tanto el océano como el arrecife de coral hablan en primera persona al ser humano, y le advierten sobre las consecuencias de sus acciones predatorias para su propia sobrevivencia.

La representación antropocéntrica fue percibida en la exposición, principalmente, en piezas que son expuestas con la intención de abordar problemas ambientales que provocan la disminución o perdida de especies marinas. Estas muestras son reconocidas por la entrevistada del equipo creativo de la exposición como de muestras conservacionistas. Al respecto plantea:

[...] tem muitas peças ali que a gente colocou que eram ponto focal de provocação, principalmente as peças que estão relacionadas com a questão da conservação dos animais marinhos [...] Então... essa questão provocativa em relação ao que a gente faz numa área, que não é correto.

2Recuperado el 11 jun. 2018 de: https://www.youtube.com/watch?v=QBVyS5-iNLk. ${ }^{3}$ Recuperado el 15 sep. 2018 de: https://www.youtube.com/watch?v=ZeytbM65wLI. 
Quando a gente colocou as peças, realmente já tinham esse objetivo. De fazer essa parte, de ser um pouco mais, de contestar, assim, um pouco mais esses hábitos culturais. Mostrar como era no passado e comparar com o que se tem agora. [...]

Isso também foi pensado nesse sentido, essa questão conservacionista. Mostrar que tem vários grupos ali que têm questões importantes em relação à conservação.

Durante el estudio fueron identificadas en la exposición, como mínimo, seis muestras de este tipo (O problema da ingestão de plásticos por tartarugas-marinhas, Os lixeiros das praias, Tubarões drasticamente reduzidos pela pesca industrial, entre otras), que ya desde el propio título explicitaban el problema ambiental abordado. En esas muestras fueron identificados problemas relacionados con la muerte de especies por la ingestión de plástico y la extinción o reducción del tamaño de especies por la pesca intensiva y comercial.

A modo de ejemplo, para entender mejor el tratamiento dado en la exposición a estos problemas ambientales, se presenta el texto de apoyo de la muestra O Problema da Ingestão de Plásticos por Tartarugas-Marinhas, expuesta en el ala cinza (gris).

En la muestra son expuestas dos tortugas marinas en preparación liquida, contenidas en un cubo de vidrio. Entre este receptáculo y las paredes de vidrio de la vitrina se dispone la información textual de apoyo en un rótulo, así como numerosos fragmentos de plástico extraídos del interior de tortugas. La información textual, en este caso, es de vital importancia para que el visitante pueda interpretar lo que se expone, así como ofrece información sobre el problema ambiental en cuestión.

\section{O Problema da Ingestão de Plásticos por Tartarugas-Marinhas}

Os poluentes sólidos, principalmente resíduos plásticos, já são um problema global de gigantesca proporção. A produção desenfreada, associada à falta de uma austera politica de destinação pósutilização, estão resultando em um catastrófico impacto nos oceanos. Dentre os grupos de animais mais afetados destaca-se o das tartarugas-marinhas, visto que costumam ingerir uma infinidade de tipos de plásticos, que acabam por colapsar o sistema digestivo, levando o animal á morte por inanição. Neste expositor podemos observar dois espécimes juvenis de tartarugas-verdes, sendo o da esquerda em condições normais e o da direita com severa inanição, com redução drástica dos tecidos, ocasionada pela ingestão de lixo plástico. Também, no entorno do tanque, estão dispostos restos de plásticos dos conteúdos estomacais de duas tartarugas-cabeçudas juvenis. Até a década eram raros os casos com tartarugas mortas desta forma, sendo agora bastantes frequentes.

Fuente: Texto asociado a la Muestra del Museo.

El problema ambiental tratado se refiere a la muerte de tortugas marinas por ingesta de plástico. El abordaje que de él se hace, queda circunscrito a causas y consecuencias relacionadas a la luz de conocimientos biológicos o ecológicos, las que son simplemente enunciadas y eximidas de cualquier reflexión que apunte a dilucidar los responsables de tales causas, los beneficiados y los perjudicados, limitando el tratamiento del problema a su dimensión biofísica. Además, tampoco se ofrece la posibilidad al visitante de dejar de ser un espectador pasivo ante el problema, pues no se ofrecen posibles soluciones o alternativas al problema en las que pueda percibirse como agente de cambio, así como tampoco se contextualiza el problema a lo local y/o regional. 
Más allá de estas muestras, problemas ambientales son enunciados como subtemas en la información textual de apoyo a otras piezas expuestas. A modo de ejemplo se presenta un fragmento extraído del texto de apoyo al caparazón de tortuga laúd expuesto en el ala cinza (gris).

[...] É impactada por diversas modalidades de pesca, destacando o espinhel-pelágico e as redes-deemalhe. Status de conservação no Brasil: criticamente ameaçada.

Fuente: Texto de apoyo asociado a la Muestra del Museo.

En el fragmento el problema aparece tratado de forma más simple y sucinta que en el ejemplo anterior, relacionando causa y consecuencia, sin siquiera una explicación que contextualice la relación.

De forma general, el tratamiento dado al medio ambiente en la exposición del Museu Oceanográfico Univali coincide con lo reportado por Fortin-Debart (2003) para museos de historia natural franceses, en cuanto a la presencia en las exposiciones de las representaciones del medio ambiente biocéntrica, ecocéntrica, y antropocéntrica. Resultado similar fue encontrado también por Marandino y Rocha (2011) en el análisis de las exposiciones del Biodôme de Montreal (Canadá) y de la Fundação Zoobotânica do Rio Grande do Sul (FZB), en Brasil.

Más específicamente, para las exposiciones del Biodôme y de la Fundação Zoobotânica, los autores reportan una mayor representatividad de la representación ecocéntrica, seguida por la antropocéntrica y la biocéntrica, mientras que para el Museu Oceanográfico Univali fue identificada una gran representatividad de la representación biocéntrica, seguida por la ecocéntrica y la antropocéntrica. Estas diferencias son comprensibles, pues las exposiciones analizadas por Marandino y Rocha (2011) son del tipo inmersiva e intentan reproducir ecosistemas naturales; mientras que la exposición del Museu Oceanográfico Univali, muestra una marcada organización taxonómica, que se centra en el protagonismo de los especímenes expuestos en vitrinas, auxiliados por información textual.

En el caso la representación antropocéntrica, Marandino y Rocha (2011) denotan la presentación de problemas ambientales relacionados con los ecosistemas representados y algunas de sus especies, pero no ahondan en las características de su presentación. Sin muchos elementos para contrastar en este sentido, es importante señalar que en la exposición del Museu Oceanográfico Univali los problemas ambientales son presentados en relación con algunas de las especies presentadas, y que son planteados en una forma que no responde a la complejidad de los mismos, probablemente ofreciendo pocas posibilidades al visitante para una reflexión crítica.

\section{Conclusiones}

La exposición del Museu Oceanográfico Univali se percibe como el resultado de un proceso de idealización y montaje más en función del acervo, los avatares del contexto y los supuestos de sus creadores, que de las expectativas y necesidades de aprendizaje de los visitantes. Si bien, una vez abierta al público, se mantiene susceptible a algunos cambios que objetivan la comunicación con el visitante, por otra parte, la informalidad e irregularidad de los procesos de retroalimentación que los sustentan, 
mantiene en la incerteza su efectividad en pos de la inteligibilidad de la exposición. Este estado de la comunicación con el visitante devela una acción educativa a la que subyace un marco de referencia conductista.

En ese contexto comunicativo, la biodiversidad zoológico-marina se presenta mediante una exhaustiva y extensiva colección de especímenes, expuestos en función de una lógica evolutiva y mediante una cuidadosa organización taxonómica que devela una representación del medio ambiente biocéntrica. Más allá de esta representación, los especímenes expuestos en el contexto de dioramas y acuarios transparentan una representación ecocéntrica del medio ambiente, potenciada por todo un arsenal de recursos museográficos como paneles y carteles con diseños de grandes animales en tamaño natural, así como con la proyección de documentales con un discurso marcadamente ecocéntrico. Por último, la representación antropocéntrica del medio ambiente fue identificada en muestras que tratan problemas ambientales en su dimensión biofísica. Estos problemas ambientales se refieren a la disminución o extinción de especies marinas por la ingestión de desechos humanos y por la pesca comercial e intensiva.

Las características comunicativas de la exposición, así como su presentación de la biodiversidad zoológico-marina en el marco de representaciones del medio ambiente biocéntrica, ecocéntrica y antropocéntrica, sumado a un tratamiento de problemas ambientales en su dimensión biofísica, lleva a pensar a la exposición del museo como una acción educativo-ambiental de resultados inciertos, enmarcada en un enfoque naturalista y conservacionista de la educación ambiental.

La constatación de la exposición del Museu Oceanográfico Univali como un instrumento de producción de sentidos sobre el medio ambiente y los problemas que lo afectan, lleva a pensar al museo de historia natural, en sentido amplio, como un espacio con potencialidades para la educación ambiental de sus públicos, toda vez que puede contribuir a ampliar el ámbito de formación de la ciudadanía al medio ambiente. No obstante, si como sucede en la institución objeto del estudio, el medio ambiente y sus problemas ambientales son tratados en los límites de un conocimiento especializado, y posiblemente desconectado de las realidades ambientales de sus visitantes, lleva inevitablemente a pensar al museo de historia natural como un espacio que poco pudiera estar contribuyendo a la educación ambiental de sus públicos, en el sentido de contribuir con la formación de "[...] cidadãos amorosamente engajados na transformação das relações da sociedade com a natureza" (CARVALHO, 1998, p. 24).

Ante este panorama, el museo de historia natural, como institución al servicio de la sociedad, necesita repensar en el marco de su identidad, su labor social, en dirección a reorientar su servicio público de una museología de colecciones a una museología social. En ese anhelo se inscribe el presente artículo, que a través de la lente de la museología y de la educación ambiental intenta ofrecer reflexiones útiles para contribuir con tal propósito.

\section{Agradecimiento}

Este trabajo se realizó con el apoyo de Programa para estudiantes de posgrado (PEC-PG), da Coordenação de Aperfeiçoamento de Pessoal de Nível Superior (CAPES), Brasil. 


\section{Referencias}

ALVES-MAZZOTTI, A. J.; GEWANDSZNAJDER, F. O método nas ciências naturais e sociais: pesquisa quantitativa e qualitativa. 2. ed. São Paulo: Pioneira Thompson Learning, 2000.

CARVALHO, I. C. M. Em direção ao mundo da vida: interdisciplinaridade e educação ambiental. Brasília: Instituto de Pesquisas Ecológicas, 1998.

CURY, M. X. Educação em museus: panorama, dilemas e algumas ponderações. Ensino em ReVista, Uberlândia, v. 20, n.1, p. 13-28, 2013. Recuperado el 5 sep 2018 de: http://www.seer.ufu.br/ index.php/emrevista/article/view/23206.

CURY, M. X. Exposição: concepção, montagem e avaliação. São Paulo: Annablume, 2006.

CURY, M. X. El museo dialógico y la experiencia del visitante. In: HARRIS, J. (org.). El museo dialógico y la experiencia del visitante. Taiwan: Council for Cultural Affairs: Executive Yuan and the Chinese Association of Museums, 2011. p. 36-46.

DEAN, D. Museum exhibition: theory and practice. New York: Routledge, 2002.

DELICADO, A. Para que servem os museus científicos?: funções e finalidades dos espaços de musealização da ciência. In: CONGRESSO LUSO-AFRO-BRASILEIRO DE CIÊNCIAS SOCIAIS, 8., 2004, Coimbra. Recuperado el 6 feb. 2017 de: http://www.ces.uc.pt/lab2004/pdfs/AnaDelicado.pdf.

FALK, J. H.; DIERKING, L. D.; ADAMS, M. Living in a learning society: museums and free-choice learning. In: MACDONALD, S. A companion to museum studies. Malden: Blackwell, 2006. p. 323339.

FIGURELLI, G. R. A relevância das práticas avaliativas nas rotinas dos museus. MUSAS: revista brasileira de museus e museologia, Brasília, ano 7, n. 6, p. 148-165, 2014. Recuperado el 3 dic. 2018 de: http://www.museus.gov.br/wp-content/uploads/2015/01/Revista-Musas-6.pdf.

FOLADORI, G. Contenidos metodológicos de la educación ambiental. Tópicos en Educación Ambiental, Guadalajara, México, v. 4, n. 11, p. 33-48, 2002. Recuperado el 26 ene. 2019 de: http:// www.anea.org.mx/Topicos.htm.

FORTIN-DEBART, C. Le musee de sciences naturelles, un partenaire de l'école pour une education relative a l'environnement: du message scientifique au débat de société. Vertigo: la revue électronique en sciences de l'environnement, Montréal, v. 4, n. 2, p. 1-10, 2003. DOI: https://doi. org/10.4000/vertigo.4494.

GONZÁLEZ GAUDIANO, E. Otra lectura a la historia de la educación ambiental en América Latina y el Caribe. Desenvolvimento e Meio Ambiente, Curitiba, v. 3, p. 141-158, 2001. DOI: http://dx.doi. org/10.5380/dma.v3i0.3034.

HEIN, G. E. Learning in the museum. London: Routledge, 2002.

HOOPER-GREENHILL, E. Changing values in the art museum: rethinking communication and learning. International Journal of Heritage Studies, Abingdon, v. 6, n. 1, p. 9-31, 2010. DOI: https:// doi.org/10.1080/135272500363715.

HOOPER-GREENHILL, E. Museum and education. London: Routledge, 2007.

HOOPER-GREENHILL, E. Museum and their visitors. London: Routledge, 2004.

HOOPER-GREENHILL, E. Museums and the shaping of knowledge. London: Routledge, 2003.

KURY, L. B.; CAMENIETZKI, C. Z. Ordem e natureza: coleções e cultura científica na Europa moderna. Anais do Museu Histórico Nacional, Rio de Janeiro, v. 29, p. 57-85, 1997. Recuperado el 8 oct. 2017 de: http://memoria.bn.br/DocReader/DocReader.aspx?bib=884790\&pagfis=6474. 
LAMIM-GUEDES, V. Temática socioambiental em museus de ciências: educação ambiental e a educação científica. Ambiente \& Educação: revista de educação ambiental, Rio Grande, RS, v. 22, n. 1, p. 77-95, 2017. DOI: https://doi.org/10.14295/ambeduc.v22i1.6103.

LAYRARGUES, P. P. Para onde vai a educação ambiental?: o cenário político-ideológico da educação ambiental brasileira e os desafios de uma agenda política crítica contra-hegemônica. Revista Contemporânea de Educação, Rio de Janeiro, v. 7, n. 14, p. 388-411, 2012. Recuperado el 20 ago. 2017 de: https://revistas.ufrj.br/index.php/rce/article/view/1677.

MARANDINO, M. Educação em museus de história natural: possibilidades e desafios de um programa de pesquisa. Enseñanza de las Ciencias, Barcelona, n. extra, p. 1-4, 2005.

MARANDINO, M. Museus de ciências, coleções e educação: relações necessárias. Museologia e Patrimônio, Rio de Janeiro, v. 2, n. 2, p. 1-12, 2009. Recuperado el 3 ene. 2021 de: http:// revistamuseologiaepatrimonio.mast.br/index.php/ppgpmus/article/view/63.

MARANDINO, M. Por uma didática museal: propondo bases sociológicas e epistemológicas para a análise da educação em museus. 2011. Tese (Livre Docência) - Faculdade de Educação, Universidade de São Paulo, São Paulo, 2011. Recuperado el 3 ene. 2021 de: https://www.teses.usp. br/teses/disponiveis/livredocencia/48/tde-22102014-084427/pt-br.php.

MARANDINO, M.; ROCHA, P. E. D. La biodiversidad en exposiciones inmersivas de museos de ciencias: implicaciones para educación en museos. Enseñanza de las Ciencias, Barcelona, v. 29, n. 2, p. 221-236, 2011. Recuperado el 3 ene. 2018 de: https://www.raco.cat/index.php/Ensenanza/ article/view/243834.

McMANUS, P. M. Topics in museums and science education. Studies in Science Education, Leeds, v. 20, n. 1, p. 157-182, 1992. DOI: https://doi.org/10.1080/03057269208560007.

MEYER, G. C.; MEYER, G. C. Educação em museus de ciência: diálogos, práticas e concepções. Revista Brasileira de Educação Ambiental, São Paulo, v. 9, n. 1, p. 70-86, 2014. DOI: https://doi. org/10.34024/revbea.2014.v9.1822.

SAUVÉ, L. Educación científica y educación ambiental: un cruce fecundo. Enseñanza de las Ciencias, Barcelona, v. 28, n. 1, p. 5-18, 2010. Recuperado el 3 ene. 2021 de: https://www.raco.cat/index. php/Ensenanza/article/view/189092.

SAUVÉ, L. Perspectivas curriculares para la formación de formadores en educación ambiental. In: FORO NACIONAL SOBRE LA INCORPORACIÓN DE LA PERSPECTIVA AMBIENTAL EN LA FORMACIÓN TÉCNICA Y PROFESIONAL, 1., 2003, México. Recuperado el 28 dic. 2020 de: https://www.miteco. gob.es/ca/ceneam/articulos-de-opinion/2004_11sauve_tcm34-163438.pdf.

VAN PRAËT, M. Cultures scientifiques et musées d'histoire naturelle en France. Hermès: la revue, Paris, n. 20, p. 143-149, 1996. Recuperado el 9 ene. 2018 de: https://www.cairn.info/revue-hermesla-revue-1996-2.htm.

VAN PRAËT, M. Heritage and scientific culture: the intangible in science museums in France. Museum International, Oxford, UK, v. 56, n. 1-2, p. 113-121, 2004. DOI: https://doi.org/10.1111/ j.1350-0775.2004.00465.x.

VASCONCELLOS, M. D. M. N.; GUIMARÃES, M. Educação ambiental e educação em ciências: um esforço de aproximação em um museu de ciências - MAST. Ambiente \& Educação, Rio Grande, RS, v. 11, n. 1, p. 165-174, 2006. Recuperado el 30 dic. 2020 de: https://periodicos.furg.br/ambeduc/ article/view/775. 